\title{
Validation of Eclipta dendensis Nascimento \& Santos-Silva, 2017 (nomen nudum) (Coleoptera, Cerambycidae, Cerambycinae, Rhinotragini)
}

\author{
Francisco E. de L. Nascimento (1) \& Antonio Santos-Silva \\ Museu de Zoologia, Universidade de São Paulo. Caixa Postal 42.494, 0421 8-970, São Paulo, SP, Brazil. \\ (eribnascimentofl@gmail.com; toncriss@uol.com.br)
}

Received 2 February 2018

Accepted 16 February 2018

Published 5 April 2018

DOI: $10.1590 / 1678-4766 \mathrm{e} 2018006$

\begin{abstract}
Eclipta dendensis Nascimento \& Santos Silva, 2017 (nomen nudum) is validated. The Neotropical Eclipta Bates, 1873, together with five other genera, composes a generic complex in Rhinotragini, which were previously allocated in Ommata White, 1855. In Brazil, many species of Eclipta are distributed in the Amazon and Atlantic forest regions. In this work, Eclipta dendensis sp. nov. from the Brazilian Atlantic Forest is described and illustrated.
\end{abstract}

KEYWORDS. Neotropical region, South America, taxonomy.

For the purpose of following the rules of the ICZN (1999) concerning on works issued and distributed electronically (Art. 8.5.2; 8.5.3), the work by NASCIMENTO \& SANTOS-SILVA (2017) is republished. The following text was copied from NaScimento \& SANTOS-SiLVA (2017).

Ommata White, 1855 was divided by BATEs (1873) in three groups of species, based primarily on the shape of the legs. The first group included the species with "Legs long and slender; middle femora gradually and moderately clavate". This group included four subgroups, characterized by the elytral shape: Phoenissa; Chrysaethe; Ommata; and Rhopalessa. The second group included the species with legs slender; middle femora abruptly but not very broadly clavate; elytra with sides subparallel and apex truncated. Finally, the third group included Agaone Pascoe, 1859, with legs robust, middle femora abruptly and very thickly clavate, first joint of hind tarsi greatly elongated and elytra entire.

Currently, Chrysaethe, Ommata, Rhopalessa, Eclipta, Phoenissa (= Oregostoma Audinet-Serville, 1833) and Agaone are considered distinct genera. Notwithstanding, the division between "legs long and slender" and "legs long" is completely subjective and false, as we could see in the species allocated in each group by BATES (1873). For example, the legs in Ommata (Eclipta) eirene (Newman, 1841) (currently, Eclipta eirene), are long and slender, exactly as in Ommata (Chrysaethe) beltiana Bates, 1872 (currently, Chrysaethe beltiana). In the same way, the difference in the shape of mesofemora is not true, and it is very variable in the species currently placed in Eclipta and Chrysaethe, originally allocated in these genera by BATES (1873).

As Eclipta and Chrysaethe have the elytral apex truncate, and the elytra is very variable in the species placed in Eclipta by BATES (1873), it is absolutely impossible to separate these genera based on the features originally included. However, the type species of each genus, designated by PeÑaherRera-Leiva \& TAVAKILIAN (2004), allow separating them (notably by the pronotal shape), although it would be necessary a complete revision of these genera to correctly place each species.

The new species agrees moderately well with the type species of Eclipta (Ommata (Eclipta) flavicollis Bates, 1873), mainly by the antennal, pronotal, elytral and legs shape. Thus, we are describing it in Eclipta.

According to MonNÉ (2017), Eclipta Bates, 1873 includes 58 species distributed from Mexico to southern South America. In Brazil, the species of Eclipta are distributed mainly in the Atlantic forest and some species also inhabit the Amazonian regions. The new species was described based on a specimen from the Atlantic Forest in the Bahia state, Northeast Brazil.

\section{MATERIAL AND METHODS}

Photographs were taken in the MZSP (Museu de Zoologia, Universidade de São Paulo, São Paulo, Brazil) with a Canon EOS Rebel T3i DSLR camera, Canon MP-E $65 \mathrm{~mm} \mathrm{f} / 2.81-5 \mathrm{X}$ macro lens, controlled by Zerene Stacker AutoMontage software. Measurements were taken in "mm" 
using a micrometer ocular Hensoldt/Wetzlar - Mess 10 in the Leica MZ6 stereomicroscope.

\section{RESULTS AND DISCUSSION}

\section{Eclipta dendensis sp. nov.}

(Figs 1-4)

urn:lsid:zoobank.org:pub:6A1BC28E-67CA-4DEC-884B8743F8614BD2

Eclipta dendensis Nascimento \& Santos-Silva, 2017:1 (nomen nudum).

Female. Integument black, with greenish or violaceous reflections in some areas; antennomere VIII with dark reddish-brown ring on basal quarter; antennomere IX with reddish-brown ring on basal quarter, more yellowish ventrally; antennomeres X-XI with pale yellow ring on basal third; pronotum yellow except for the transverse reddishbrown band close to distal margin; sides of prothorax mostly yellow except black area close to procoxal cavity, reddishbrown basal area and black distal area, and irregular reddishbrown macula on distal third; elytra with small reddish macula on sides of humeri; metacoxae brown maculated with reddish-brown areas; metatrochanters yellowish-brown; distal 2/3 of metatarsomere I and entire surface of II pale yellow; metatarsomere III reddish-brown on basal half, brown on lobes; metatarsomere IV reddish-brown; basal half of metatarsomere $\mathrm{V}$ reddish-brown, distal half dark brown; basal projection of abdominal ventrite I pale yellow.

Head. Rostrum (between apex of inferior ocular lobe and genal apex) in frontal view 0.8 times length of lower eye lobe. Frons finely, abundantly punctate close to clypeal area and lower eye lobes, somewhat coarser, sparser on inverted V-shaped central area; with short, decumbent, sparse yellowish setae, distinctly more abundant close to lower eye lobes. Area between lower eye lobes finely, abundantly punctate (punctures as on frontal area close to lower eye lobes); with short, decumbent, moderately abundant yellowish setae close to eyes, sparser toward coronal suture, interspersed with long, erect, sparse yellowish setae close to eyes. Area between antennal tubercles and prothoracic margin moderately coarsely, densely, confluently punctate with minute, decumbent, sparse yellowish setae interspersed with long, erect yellowish setae. Antennal tubercles gradually minutely punctate toward apex with short, erect, moderately sparse yellowish setae. Coronal suture distinct from clypeus to area between antennal tubercles. Postclypeal area finely punctate basally, smooth toward apex; with short, decumbent, sparse yellowish setae on punctate area, interspersed with long, erect yellowish setae, glabrous on smooth area. Labrum minutely, abundantly punctate basally, smooth toward apex; with long, erect, yellowish setae laterally and brush of yellowish setae on distal margin. Outer edge of mandibles, moderately finely, abundantly punctate on basal $2 / 3$ (punctures, confluent and oblong); with some long, erect yellowish setae. Area behind lower eye lobes with short, decumbent yellowish setae close to eye; remaining surface with long, erect, sparse yellowish setae. Genae finely, moderately sparsely punctate ventrally, finely, densely punctate dorsally (somewhat striate close to eye), smooth toward apex; with minute, decumbent, sparse yellowish setae, ventrally interspersed with some long, erect yellowish setae. Gular region smooth close to prothorax, finely, sparsely punctate toward submentum; glabrous close to prothorax, with short and long, erect, sparse yellowish setae toward submentum. Submentum finely striate-punctate; with short and long, erect, moderately sparse yellowish setae. Distance between upper eye lobes 0.65 times length of scape; distance between lower eye lobes in frontal view 0.55 times length of scape. Antennae 1.2 times elytral length, reaching distal fifth of elytra; ventral side of scape, pedicel and antennomeres III-VII with long, erect, thick, dark setae, gradually shorter, sparser toward VII; antennal formula (ratio) based on antennomere III: scape $=0.82$; pedicel $=0.29$; IV $=0.70 ; \mathrm{V}=0.88 ; \mathrm{VI}=0.76 ; \mathrm{VII}=0.70 ; \mathrm{VIII}=0.59 ; \mathrm{IX}=$ $0.50 ; \mathrm{X}=0.50 ; \mathrm{XI}=0.67$.

Thorax. Prothorax subcylindrical, 1.2 times longer than wide, laterally slightly rounded. Pronotum coarsely punctate-reticulate, with long, erect, moderately abundant yellowish setae and slightly conspicuous yellowishwhite pubescence basally. Sides of prothorax coarsely, abundantly punctate on yellowish area, obliquely striate on basal reddish-brown area, smoother on distal black area; with yellowish-white pubescence on basal half of yellow area; with short and long, erect yellowish setae except subglabrous distal area. Prosternum coarsely, abundantly punctate on basal half, mostly smooth on distal half; with whitish pubescence interspersed with long, erect, whitish setae on punctate area, glabrous on smooth area. Prosternal process narrowed centrally, notably triangularly expanded toward apex; triangularly depressed, centrally carinate. Mesoventrite centrally with whitish pubescence not obscuring integument, laterally slightly conspicuous. Mesanepisternum, mesepimeron and metanepisternum with whitish pubescence partially obscuring integument, interspersed with long, erect whitish setae. Metaventrite minutely, densely punctate, less dense toward central smooth area, laterally interspersed with fine, moderately abundant punctures; with whitish pubescence, gradually sparser toward center, interspersed with long, erect whitish setae. Scutellum longitudinally sulcate centrally, mainly after midlength, with minute whitish setae not obscuring integument. Elytra reaching apex of fourth abdominal segment; outer edges convergent from base to slightly after apex of basal third, parallel-sided toward apex; apex slightly obliquely truncate, with minute projection at sutural angle; coarsely, punctate-reticulate throughout; with minute, moderately abundant yellowish setae interspersed with long, erect yellowish setae (longer, more abundant on basal third). Legs: apex of metafemora surpassing elytral apex. Metatarsomere I 1.45 times as long as II-III together.

Abdomen. Ventrite I minutely, densely punctate laterally, interspersed with fine punctures, smooth centrally; ventrites II- 

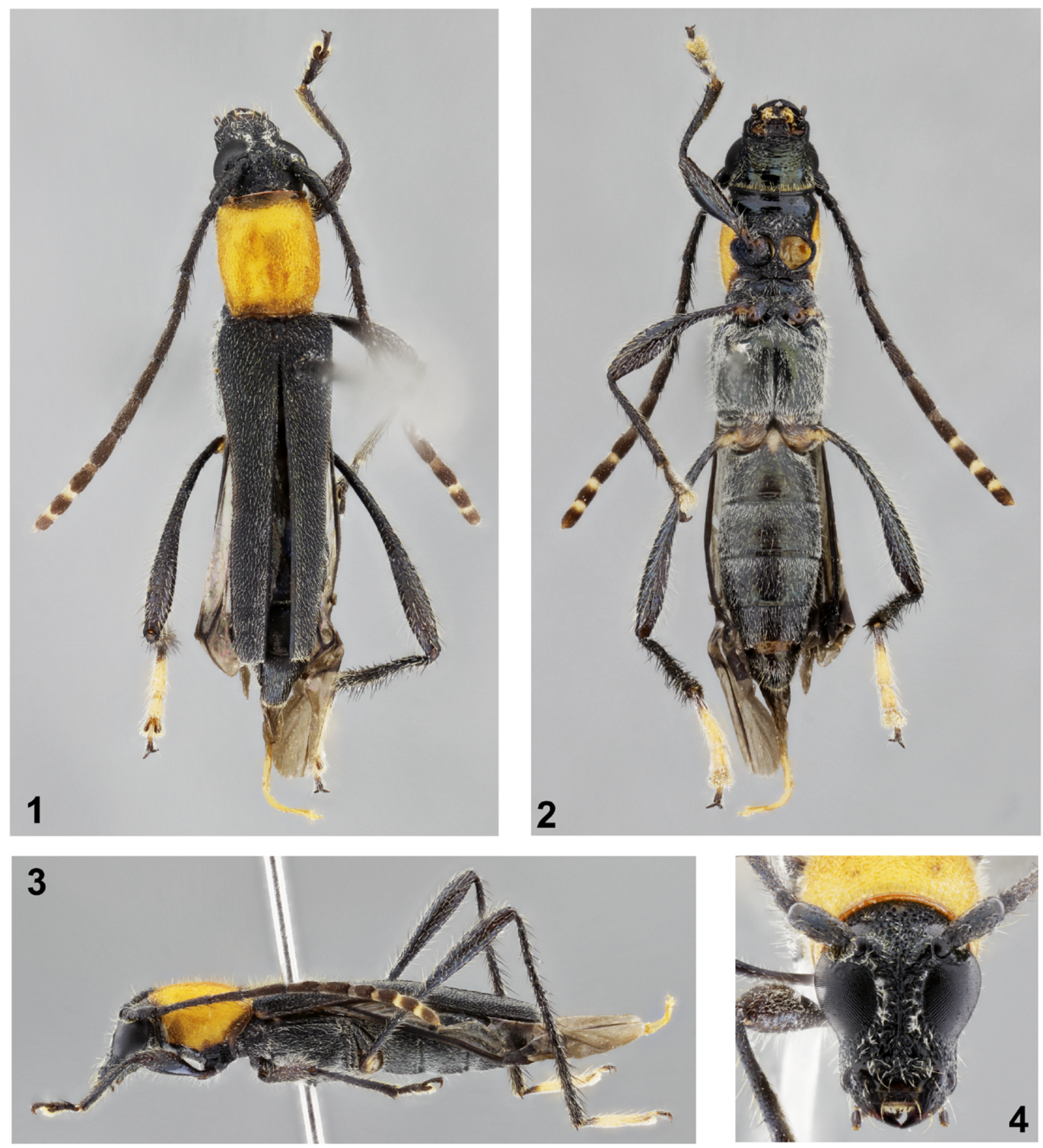

Figs 1-4. Eclipta dendensis sp. nov., holotype $q$, images copied from NAScimento \& SANTOS-SiLvA (2017): 1, dorsal habitus; 2, ventral habitus; 3. lateral habitus; 4 , head, frontal view. Total length: $8,55 \mathrm{~mm}$.

IV minutely, densely punctate interspersed with fine punctures, except smooth center-distal area; ventrite $\mathrm{V}$ minutely, densely punctate interspersed with fine punctures, except smooth basal region; laterally with whitish, decumbent, abundant whitish setae (not obscuring integument), interspersed with long, erect whitish setae, gradually sparser toward center (glabrous on center-distal area of ventrite I and basal quarter of $\mathrm{V}$ ); apex of ventrite $\mathrm{V}$ rounded.
Dimensions in mm (holotype 9 ). Total length (from mandibular apex to abdominal apex), 8.55; prothorax: length, 1.75; basal width, 1.26; distal width, 1.25 ; widest prothoracic width, 1.45; humeral width, 1.60; elytral length, 5.00.

Type material. Holotype female from BRAZIL, Bahia: Igrapiúna (Reserva Ecológica da Michelin, Pacangê; 1350'16.0”'S / 39¹4'28.9'W; 139 m), 21-22.V.2012, M. Aragão, E. Menezes \& E. Mota col. (MZSP). 
Etymology. The name refers to the region where the holotype was collected, popularly known as Costa do Dendê.

Remarks. Eclipta dendensis sp. nov. resembles $E$. eirene (Newman, 1841) by the metatarsi mostly pale yellow, but differs as follows (female): distal antennomeres with basal light ring; pronotum coarsely punctate-reticulate; distal $2 / 3$ of outer edge of the elytra parallel-sided; distal third of the elytra not dehiscent; elytra not narrowed toward apex from midlength; elytral apex reaching apex of fourth abdominal segment; apex of metafemora slightly surpassing elytral apex. In E. eirene, the distal antennomeres are not ringed, pronotum is moderately finely and abundantly punctate, distal $2 / 3$ of outer edge of the elytra is somewhat concave, distal third of the elytra is dehiscent, elytra narrowed toward apex from midlength, elytral apex reaching at about midlength of third abdominal segment (sometimes the apex of third segment and apex of metafemora distinctly surpasses the elytral apex). It also resembles $E$. thoracica (Bates, 1873), but differs mainly by the metatarsi mostly pale yellow which is darker in E. thoracica.
Acknowledgments. The authors are grateful to Dr. Kevin Flasher, manager in the Bahia's plantations Michelin Ltda., for all support; to Dr. Sergio Ricardo Andena of the MZFS (Museu de Zoologia Universidade Estadual de Feira de Santana, Bahia, Brazil) and Marcos Aragão (MZFS) for the assistance and fieldwork.

\section{REFERENCES}

BATES, H. W. 1873. Notes on the longicorn Coleoptera of tropical America. The Annals and Magazine of Natural History 11(4):21-45.

ICZN - INTERNATIONAL COMMISSION ON ZOOLOGICAL NOMENCLATURE. 1999. International Code of Zoological Nomenclature. 4ed. London, International Trust for Zoological Nomenclature. $x x x+306 p$.

MonNÉ, M. A. 2017. Catalogue of the Cerambycidae (Coleoptera) of the Neotropical Region. Part I. Subfamily Cerambycinae. Available at $<$ http://www.cerambyxcat.com/>. Accessed on 10 May 2017.

Nascimento, F. E. L. \& Santos-Silva, A. 2017. New species of Eclipta from the Brazilian Atlantic Rainforest (Coleoptera, Cerambycidae, Cerambycinae, Rhinotragini). Iheringia, Série Zoologia 107:e2017027. Available at $<$ http://www.scielo.br/scielo. php?script=sci_arttext\&pid=S0073-47212017000100227\&lng=en\& nrm=iso $>$. Accessed on $01 \mathrm{Feb} 2018$.

Peñaherrera-Leiva, A. Y. \& TavaKilian, G. L. 2004. Nouvelles espèces et nouveaux genres de Rhinotragini (Coleoptera, Cerambycidae). III. Coléoptères 10(10):119-150. 